\title{
A questão soteriológica na Torá
}

\section{ELIATHAN CARVALHO LEITE ${ }^{1}$ JOSUÉ PEREIRA CORRÊA ${ }^{2}$}

\begin{abstract}
Resumo: Na teologia, o termo soteriologia é utilizado para designar o estudo da salvação. Além disso, há diversos outros contextos que se relacionam com a área, como o secular e o político; o que atribui uma natureza ampla ao estudo do tema. Tendo em mente essa abrangência, potencialmente vasta, o presente estudo circunscreve-se a analisar, sem pretensões de apresentar uma pesquisa exaustiva, como o tema da soteriologia é definido e apresentado nos cinco primeiros livros da Bíblia, tendo em conta a sua importância para o desenvolvimento da concepção soteriológica do restante das Escrituras e para a teologia como um todo. Para tal, foi realizada uma análise das ocorrências de palavras e expressões do campo semântico da soteriologia em cada um dos livros que compõem a Torá, tomando como base os descritores expostos por Blazen. Trata-se, portanto, de uma pesquisa de análise documental, baseando-se nos conceitos extraídos de uma prévia revisão bibliográfica. Por meio deste estudo, concluiu-se que os primeiros cinco livros da Bíblia propõem um desenvolvimento teológico linear e progressivo sobre o tema soteriológico, e que cada um deles lida com um ou mais conceitos internos da área, variando a ênfase conforme a intenção do livro.
\end{abstract}

Palavras-chave: soteriologia; salvação; Torá.

\section{The Torah's soteriological issue}

\begin{abstract}
In theology, the term soteriology is used to designate the study of salvation. In addition, there are several other contexts that relate to the area, such as the secular and political contexts, which attributes a broad nature to the study of the theme. Bearing in mind this potentially vast scope, the present study is limited to analyzing, without pretending to present an exhaustive research, how the theme of soteriology is defined and presented in the first five books of the Bible, considering its importance for the development of the soteriological conception of the rest of the Scriptures and for theology as a whole. To this end, an analysis of the occurrences of words and expressions in the semantic field of soteriology was carried out in each of the books that make up

\footnotetext{
1 Mestrando em Teoria Literária pela Universidade Estadual de Campinas (UNICAMP). Bacharel em Teologia pela Faculdade Adventista de Teologia (FAT), no Centro Universitário Adventista de São Paulo (UNASP). E-mail: eliathan.carvalho.l@gmail.com

2 Pós-graduando em Ensino de Filosofia e Sociologia pela Faculdade Venda Nova do Imigrante; Bacharel em Teologia Bacharel pela Faculdade
} Adventista de Teologia (FAT), no Centro Universitário Adventista de São Paulo (UNASP). E-mail: josuepcorrea@gmail.com
\end{abstract}


Torah, based on the descriptors exposed by Blazen. It is, therefore, a document analysis research, based on the concepts extracted from a previous bibliographic review. It was concluded, through this study, that the first five books of the Bible propose a linear and progressive theological development on the soteriological theme and that each one deals with one or more internal concepts of the area, varying the emphasis according to the intention of the book.

Keywords: soteriology; salvation; Torah.

Soteriologia é um termo técnico para o estudo da salvação. Tal estudo, de forma geral, é tido como algo amplamente extenso, devido à pluralidade de contextos aos quais o vocábulo pode ser aplicado, como em sentido secular e político, por exemplo. No âmbito cristão, o termo é inevitavelmente relacionado a Cristo e sua missão. Ainda assim, diversas discussões são apresentadas nesse sentido, tais como a forma como de fato tal salvação ocorre, a relação divina com o processo, o desenvolvimento da salvação etc. (MACGRATH, 2005).

Diante desse cenário, diversos autores têm buscado explanar tais assuntos em suas pesquisas sistêmicas. Erickson (2015), por exemplo, tratando acerca do tema, afirma que a salvação não pode ser compreendida como um conceito simples e único, mas como algo que possui seis aspectos objetivos, definidos pelos seguintes descritores: a união com Cristo, a justificação, a adoção, a santificação, a perseverança e a glorificação.

Mediante essa percepção ampla, o presente trabalho busca analisar, de forma sucinta e breve, como o tema da soteriologia é definido e desenvolvido nos cinco primeiros livros da Bíblia, tendo em mente a sua importância para o desenvolvimento da concepção soteriológica do restante das Escrituras e para a teologia como um todo.

Para isso, uma análise das ocorrências de termos do campo semântico da soteriologia será realizada em cada um dos livros que compõem a Torá, tomando como base os descritores expostos por Blazen (2011). Em sequência, será feita uma breve análise de outras narrativas ou conceitos relevantes ao objetivo central deste trabalho. Trata-se, portanto, de uma pesquisa de análise documental, tomando como base os conceitos extraídos de uma prévia revisão bibliográfica.

\section{Soteriologia: definição e desenvolvimento do tema na Torá}

Diante da proposta de abordar, de forma breve e sucinta, o modo como o tema da soteriologia é trabalhado nos cinco primeiros livros da Bíblia, preconizando sua importância para o desenvolvimento da Bíblia e da teologia cristã, uma análise específica de cada livro será realizada, conforme pode ser observada a seguir.

\section{A soteriologia no Gênesis}

Sendo o primeiro livro do cânon sagrado, Gênesis apresenta uma série de introduções para os conceitos, ideias e realidades que estarão presentes ao longo das Escrituras. Em outros termos, 
todas as problemáticas e temas presentes ao longo da Bíblia estabelecem raiz nesse livro; inclusive no que diz respeito à soteriologia (FINGUERMAN, 2005).

Mediante análise do livro de Gênesis, nota-se que várias propostas de estruturação interna da obra já foram apresentadas por estudiosos ao longo dos anos. Nichol (2011), por exemplo, propõe um esboço que contempla quatro blocos (Gn 1:1-11:26; 11:27-26:35; 27:1-36:43; 37:150:26) subdivididos em microsseções diversas, que tomam como base primordial para divisão os sujeitos que as compõem. House (2005), no que lhe concerne, propõe uma divisão composta por sete seções (Gn 1-2; 3:1-6:4; 6:5-11:9; 11:20-25:18; 25:19-28:9; 28:10-36:43; 37-50), demarcadas mediante evidenciação das ações de $Y H W H$ nas narrativas.

Dentre as propostas de divisão existentes, adotar-se-á no presente trabalho (com algumas adaptações) aquela desenvolvida e defendida por Thomas (2011), que delimita o livro a partir do

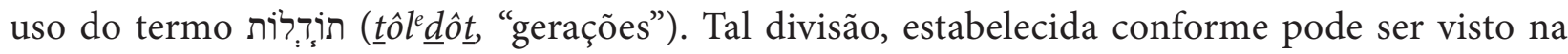
tabela 1, apresenta de forma mais clara o contexto da progressão do conceito de salvação.

Tabela 1 - Esboço do Livro de Gênesis

\begin{tabular}{|c|l|l|}
\hline \multicolumn{2}{|c|}{ Seções } & \multicolumn{1}{c|}{ Gn 1-4 } \\
\hline I & \multicolumn{2}{c|}{ Gescrição Temática } \\
\hline I.1 & Gn 1:1-2:3 & Narrativa da Criação \\
\hline I.2 & Gn 2:3-4:26 & 2a Narrativa da Criação, Queda, Caim e Abel \\
\hline II & \multicolumn{2}{c|}{ Gn 11-50 } \\
\hline II.1 & Gn 5:1-6:8 & Genealogias até Noé \\
\hline II.2 & Gn 6:9-9:29 & Noé e o Dilúvio \\
\hline III & & \\
\hline III.1 & Gn 10:1-10:31 & Genealogias até Abraão \\
\hline III.2 & Gn 10:32-11:09 & Torre de Babel \\
\hline III.3 & Gn 11:10-11:26 & Genealogias até Abraão \\
\hline III.4 & Gn 11:27-25:11 & Abraão \\
\hline III.5 & Gn 25:11-25:18 & Genealogia de Ismael \\
\hline III.6 & Gn 25:19-35:29 & Isaque \\
\hline III.7 & Gn 36:1-37:1 & Genealogia de Esaú \\
\hline III.8 & Gn 37:2-50:26 & Jacó/José \\
\hline
\end{tabular}

Fonte: Adaptado de Thomas (2011).

Uma análise seccional do livro permite observar elementos relevantes para a extração de sua percepção soteriológica. Isso porque a progressão do livro apresenta de forma clara o desenvolvimento de uma compreensão acerca do que é salvação, visto que o conceito em análise é trabalhado por diversas vezes nas narrativas, mesmo que na aplicação de termos mais incomuns ao trato do tema ou mesmo de outros que apresentam carga temática implícita - conforme explorado adiante.

Tomando como base a divisão proposta por Thomas (2011), já exposta acima, o primeiro marco de divisão de seção do livro é apresentado em Gênesis 2:4, encerrando tal seção ao fim do capítulo 4. Esse bloco apresenta, de forma genérica, uma das narrativas da criação, a queda do homem e a história de Caim e Abel. Alguns conceitos caros ao imaginário bíblico são desenvolvidos em meio a essas narrativas, como a apresentação do surgimento da problemática do pecado (o rebelar-se contra YHWH - Gn 3), o que gera a necessidade da salvação (Gn 3:15). O meio de 
resolução do problema também é apresentado de forma embrionária já no início do capítulo 4 (v. 3-5), mesmo que tal elemento já tenha surgido em meio a alusões registradas ainda no capítulo 3 (v. 21), como a confecção da primeira roupa humana a partir de peles de animais, o que sugere que "apenas Deus poderia prover uma cobertura adequada para o pecado" (MACARTHUR, 2005, p. 18). Tudo isso é desenvolvido mediante a promessa implícita de uma situação em que a problemática inicial seria resolvida (Gn 3:15, ver Ap 21-22).

Além da primeira seção apresentar um caráter mais genérico de 'ā $\underline{d a m}$ como "humanidade", é possível observar, também, um relevante interesse do texto na relação individual que ocorre no processo de salvação. Isso fica mais claro quando Caim e Abel devem oferecer seus sacrifícios no capítulo 4, recaindo diretamente sobre eles o juízo de $Y H W H$, pautado em suas escolhas (Gn 4:46) (BARTON; MUDDIMAN, 2001).

A próxima seção do livro, introduzida no capítulo 5 e iniciada, de fato, no capítulo 6 , aborda uma evolução dessa questão. $\mathrm{O}$ aspecto individual perde considerável força no processo externo de salvação, que é exercido, agora, em modelo patriarcal. Isso é evidenciado em Gênesis 6:8-9, onde, embora Noé tenha achado graça aos olhos de YHWH (momento em que o conceito é introduzido de forma explícita no livro), sendo justo e íntegro, não apenas ele é salvo, mas toda a sua casa/família.

Ainda na história de Noé, outros aspectos soteriológicos são introduzidos de forma embrionária, tais como uma legislação mais explícita sendo proferida por YHWH (Gn. 9) e um anúncio dos processos cúlticos e sacrificiais (Gn 8:20), que seriam melhor desenvolvidos posteriormente.

Uma terceira etapa do desenvolvimento progressivo da salvação pode ser observada no grande bloco que é anunciado no capítulo 10 e iniciado no capítulo 11 . O sistema patriarcal, já introduzido por meio da história de Noé, é agora desenvolvido mais amplamente, quando $Y H W H$ institui um povo para si. A salvação agora é praticada em caráter representativo por toda uma nação; o que fica claro mediante o chamado de $Y H W H$ ao patriarca Abraão, registrado em Gênesis 12:1-13 (FINGUERMAN, 2005).

É nesse contexto que diversos termos pertencentes ao campo semântico de "salvação" surgem, conforme pode ser visto na tabela 2, abaixo. Tais termos chamam a atenção de forma especial para a história de dois personagens bíblicos, que serão logo exploradas: Jacó e Ló. ${ }^{3}$

Tabela 2 - Ocorrências terminológicas do campo semântico de salvação Libertação, ideia de resgatar, extrair, retirar נצasal)

\begin{tabular}{|l|l|l|}
\hline Ocorrência & Sentido & Contexto \\
\hline Gn 31:9 & tomar & Tomar o gado \\
\hline Gn 31:16 & tirar & YHWH retirar as riquezas \\
\hline Gn 32:11 & livrar & Pedido de livramento \\
\hline Gn 32:30 & ser salvo & Reconhecimento da salvação \\
\hline Gn 37:21 & livrar & Ruben poupa a vida de José \\
\hline Gn 37:22 & livrar & Ruben poupa a vida de José \\
\hline גאל Resgatador, o que paga o resgate \\
\hline
\end{tabular}

\footnotetext{
3 Tal noção fica clara mediante nota de que, das 12 ocorrências dos termos analisados, 8 ocorrem - diretamente ou mediante forte conexão na história de Jacó (Gn 31-37), ao passo que as demais podem ser vistas na história do sobrinho de Abraão (Gn 19).
} 


\begin{tabular}{|c|c|c|}
\hline Ocorrência & Sentido & Contexto \\
\hline Gn 48:16 & livrar & Oração de José, o anjo que livra do mal \\
\hline \multicolumn{3}{|c|}{ Libertação com ênfase em segurança } \\
\hline Ocorrência & Sentido & Contexto \\
\hline Gn 19:17 & livrar & Anjos pedem a Ló que se livre e se salve \\
\hline Gn 19:19 & escapar & Ló diz que não pode escapar para o monte \\
\hline Gn 19:20 & fugir & Ló pede ao anjo para fugir de Zoar \\
\hline Gn 19:22 & refugiar & O anjo diz que Ló pode ir se refugiar em Zoar \\
\hline \multicolumn{3}{|c|}{ יִשישוּקה Salvação } \\
\hline Ocorrência & Sentido & Contexto \\
\hline Gn 49:18 & salvação & Jacó espera a salvação em $Y H W H$ \\
\hline
\end{tabular}

Fonte: elaborado pelo autor, 2020.

As histórias destacadas levantam elementos fundamentais para a percepção soteriológica no livro de Gênesis. O termo נצל (nasal, "resgatar, extrair") surge seis vezes na história de Jacó, sendo que, em duas dessas ocorrências (Gn 31:9-16), o conceito não aparenta possuir um caráter salvífico. Nas demais ocorrências, no entanto, aspectos soteriológicos são claramente observáveis.

Duas ocorrências do termo podem ser notadas no capítulo 32; capítulo que narra, primordialmente, o reencontro entre Jacó e Esaú. Toda a narrativa é construída mediante tensão constante resultante da expectativa da reação de Esaú frente a Jacó; enquanto as ações do último são sempre marcadas por medo e apreensão (Gn 32:7). Tal situação leva Jacó a orar e pedir o livramento (salvação) de YHWH diante de seu irmão, pois pensava que este intencionava matá-lo.

A segunda ocorrência de נצל (nasal, "resgatar, extrair") do referido capítulo pode ser observada no verso 30. Ainda em meio a um compasso de tensão e expectativa, Jacó entra em luta com um ser celestial em Peniel, e, após o fim da luta, reconhece que havia visto a $Y H W H$ face a face, mas que, ainda assim, sua vida havia sido salva (נצל, nāsal).

Novo uso de termos desta cadeia semântica é atribuído a Jacó apenas nos momentos finais de sua vida. Primeiramente, ao abençoar os filhos de José, ele pede a benção de $Y H W H$ e do Anjo que o havia livrado/salvo (em provável referência ao incidente de Peniel). Em momentos posteriores, ao proferir as bênçãos aos doze patriarcas, ele afirma que possui esperança na salvação de YHWH (sendo essa a única ocorrência direta do substantivo yēšûa', salvação, no livro).

As demais ocorrências dos termos em análise se concentram no capítulo 19 de Gênesis. Tal capítulo narra a salvação de Ló e de sua família, frente ao juízo iminente que seria derramado sobre as cidades de Sodoma e Gomorra. Nesse contexto, o termo מלט (mälat, livrar/libertar) surge quatro vezes no diálogo de fuga, empreendido entre Ló e os anjos.

Além dos conceitos expressados mediante os termos já mencionados, outros também são brevemente inseridos no livro de Gênesis; muito embora sejam apenas melhor desenvolvidos nos livros subsequentes. Dentre esses conceitos, é possível ressaltar aqueles que envolvem a continuidade do sistema sacrificial e a relação salvífica na $b^{e}$ rît (aliança).

Em todo caso, o livro de Gênesis apresenta, em caráter introdutório, todo o desenvolvimento do conceito soteriológico da Torá, e, consequentemente, da Bíblia. De antemão, o livro apresenta a situação problemática e sua causa, que ocasionam a necessidade de salvação. Além disso, os meios e a situação de resolução do problema também são apresentados, a partir do sistema sacrificial. 
Além disso, as narrativas do livro apresentam, de forma enfática, diversos outros aspectos fundamentais ao estudo soteriológico, como o fato de que a salvação pode ser cosmológica (Ló) ou temporal (Jacó); embora, em todo caso, YHWH seja apresentado como responsável por essa salvação, sendo libertador/resgatador. $\mathrm{O}$ aspecto da graça como premissa de salvação é também introduzido, além dos conceitos de eleição de um representante para abençoar e da salvação por meio de um sistema cúltico/sacrifical.

\section{A Soteriologia no êxodo}

Em breve análise do livro de Êxodo, a partir de uma perspectiva soteriológica, nota-se uma forte mensagem salvífica logo no primeiro capítulo. O surgimento das ações de $Y H W H$ no livro ocorre em associação ao livramento dos bebês judeus sentenciados à morte pelo Faraó, graças ao temor das parteiras (Êx 1:17). Logo após, YHWH se lembra de Israel e da promessa que fez a Abraão, Isaque e Jacó, efetuando o chamado de Moisés para libertação do povo (Êx 2:23 e 25).

No livro em questão, a figura de $Y H W H$ está intimamente atrelada ao livramento e salvação de seu povo eleito. Para uma análise um pouco mais apurada, compartimentar o livro e frisar seus aspectos soteriológicos são duas ações importantes.

Quando se fala da divisão do livro de Êxodo, as possibilidades são muitas, seja mediante atenção ao foco da análise do autor ou de outros aspectos relacionados. House (2005, p. 110), por exemplo, divide o livro de Êxodo em cinco partes que "revelam o propósito básico do livro de explicar a singularidade de Deus e sua presença no meio do povo". Já no comentário de Brown, Fitzmyer e Murphy (2007), a divisão é feita a partir de duas seções interligadas, a saber: Êxodo 1:1-15:21 - libertação dos judeus do jugo faraônico no Egito - e Êxodo 12:37-40:38 - caminhada desde o Egito até o monte Sinai.

Tendo em mente o objetivo do presente artigo, a divisão de Brown, Fitzmyer e Murphy (2007) em duas partes será adotada, mediante pequena adaptação de nomenclatura, a saber: a libertação do povo hebreu (Êx 1:1-15:21) e o início da caminhada rumo a Canaã (Êx 12:37 40:38). Essa divisão será adotada em razão de sua fundamentação metodológica, que leva em consideração primária as ocorrências terminológicas do livro, conforme pode ser observado na tabela 3, abaixo.

Tabela 3 - Divisão do livro

\begin{tabular}{|l|l|}
\hline $\begin{array}{l}\text { A libertação do povo hebreu } \\
\text { (Êx 1:1-15:21) }\end{array}$ & Início da caminhada rumo a Canaã (Êx 12:37-40:38) \\
\hline Pādah e G G’al & Kạpar \\
\hline
\end{tabular}

Fonte: Adaptado de Brown, Fitzmyer e Murphy (2007).

Levando em consideração os aspectos objetivos da salvação, conforme apresentados por Erickson (2015), o livro de Êxodo é fortemente demarcado pelas ideias de libertação (associada ao conceito de justificação que, para Erickson [2015], aparece em um contexto forense conferindo justiça ao réu, para assim libertá-lo) e resgate (que se associa ao conceito de adoção, o qual confere novamente ao homem uma posição favorável junto a $Y H W H$, assim como o resgate que é feito por parte daquele que redime), conforme pode ser notado mediante análise da tabela 4 . 
Tabela 4 - Ocorrências de libertação e resgate

\begin{tabular}{|c|c|c|c|}
\hline Termos & Ocorrências & Referência bíblica & Contexto \\
\hline$P a \bar{a} \underline{d} a h$ & 4 & Êx 13:13, 15; 21:8; 34:20; & $\begin{array}{l}\text { Resgate de primogênitos. } \\
\text { Resgate de uma filha vendida como serva. }\end{array}$ \\
\hline Gạal & 2 & Êx $6: 6 ; 15: 13$; & Libertação do povo. \\
\hline Kapar & 6 & Êx 21:30; 29:33, 36f; 30:10, 12, 15f; & $\begin{array}{l}\text { Resgate de primogênitos. } \\
\text { Cerimônias do santuário. }\end{array}$ \\
\hline
\end{tabular}

Fonte: elaborado pelo autor, 2020.

Tais aspectos são conectados ao longo do livro através do uso dos termos pādah (resgatar, libertar) e gåal (redimir). Vaz (1984, p. 61) argumenta a respeito desse uso terminológico, defendendo que "na literatura do Antigo Testamento o conteúdo teológico da libertação de Israel por parte de $Y H W H$ tem a sua correia de transmissão privilegiada nesses verbos".

Tal percepção se mostra importante, devido ao fato de que o conceito teológico de libertação ao longo da Bíblia tem seu embrião neste desenvolvimento do Êxodo. Nesse livro, portanto, o uso dos termos pā $\underline{d} a h$ e gáal, segundo Von Rad (1973, p. 85), evidenciam que "a ideia do 'resgate' considera o evento salvífico não mais a partir do seu aspecto bélico, mas um ato jurídico de libertação por parte de Javé." Essa conclusão de Von Rad (1973) estabelece a ideia de que YHWH não está, nesta cena, apenas livrando o povo de Israel da escravidão do Egito, mas também os libertando da prisão do pecado para serem seu povo.

Além desses aspectos fundamentais, nota-se que, especialmente na segunda parte do livro, surge a articulação de outros elementos soteriológicos como o conceito de "expiação"; conceito que, em conexão com o santuário, começará a ser desenvolvido no texto bíblico. O vocábulo empregado nesse contexto é kapar, o qual é repetido por seis vezes na narrativa (Êx 21:30; 29:33, 36f; 30:10, 12, 15f) - uma boa evidência da forte ênfase desse aspecto. Como esse conceito está ligado ao santuário, cinco das seis vezes em que o termo kapar surge é no contexto cerimonial (Êx 29:33, 36f; 30:10, 12, 15f). Dessa forma, ainda no Êxodo, não é possível desvincular a ideia de expiação da noção de sacrifício substitutivo, conforme será melhor trabalhado no livro de Levítico.

Nesse sentido, o livro de Exxodo apresenta YHWH como um Deus que está disposto a libertar seu povo (Êx 3:7-8). Isso fica claro quando se considera que "em várias ocasiões Deus livrou seu povo de opressões exercidas por outros povos. [Afinal,] o ponto central da salvação no Antigo Testamento foi o livramento de Israel da escravidão egípcia” (MODES, 2014, p. 40). Tal libertação envolve um aspecto jurídico (observável a partir do uso dos termos pāa $\underline{d} a h$ e gáal), pois seu povo está preso, historicamente, no Egito, mas também está preso, soteriologicamente, devido aos seus pecados, e precisa pagar a pena por suas transgressões. Logo, para que YHWH liberte seu povo, a pena precisa ser paga; dessa forma, ao pagar a dívida, $Y H W H$ se torna seu resgatador e os pecados do ser humano são expiados (Êx 12:3, 5, 6, 12, 13).

\section{A Soriteriologia em Levítico}

Para a elaboração da estrutura do livro de Levítico foram analisadas as propostas de estruturação apresentadas por Henry (2003) e Nichol (2011), resultando na divisão disposta na tabela 5. Tal tabela registra o volume de ocorrências de termos do campo semântico da salvação, expondo, em sequência, o contexto das ocorrências. 
Tabela 5 - Ocorrências de resgate e purificação mediante seções

\begin{tabular}{|l|l|l|}
\hline Seção & Ocorrências - $\mathbf{g} \underline{a}^{\prime} \boldsymbol{a l}$ e $\boldsymbol{k} \hat{\mathbf{p}} \mathbf{p} \hat{\mathbf{u}} \boldsymbol{r}$ & Contexto \\
\hline Lv. $1-7$ & 13 & Leis a respeito de ofertas e sacrifícios \\
\hline Lv. $8-10$ & 4 & A ordenação de Arão e de seus filhos para serem sacerdotes \\
\hline Lv. $11-15$ & 7 & $\begin{array}{l}\text { Leis a respeito de pureza e impureza rituais (acerca da } \\
\text { santidade) }\end{array}$ \\
\hline Lv. 16 & 11 & O dia do perdão \\
\hline Lv. $17-27$ & $3+15$ gael & Leis a respeito da vida santa e adoração santa \\
\hline
\end{tabular}

Fonte: elaborado pelo autor, 2020.

Em uma pesquisa preliminar de tais seções, é possível encontrar no livro de Levítico termos de cunho soteriológico, tais como: גאל (gäal) e כפר (kîpĥur). Esses aparecem em torno de 53 vezes no livro. O capítulo que apresenta maior concentração de termos soteriológicos é o 16, que trata acerca do dia da expiação. Onze referências soteriológicas são registradas neste capítulo, conforme já exposto na tabela 5 .

Dentre as principais ocorrências do livro, consta Levítico 17:11, em que é apresentado o princípio base e fundamental da expiação de pecados: a vida da carne está no sangue, e ela é colocada no altar para fazer expiação pela vida do pecador (FERREIRA, 2006). Groningen (1997), comentando o texto, afirma que o sangue tinha um papel importante no sacrifício, pois seria pelo sangue que a expiação e o perdão seriam efetivados. Assim, a vida presente no sangue removia a morte e suas causas; de forma até mesmo poética, a vida seria, assim, um meio para a própria vida.

Tal concepção mostra, de forma clara, o aspecto fundamentador da salvação no livro de Levítico: o sangue como expiação, vertido pela vida do pecador. Este aspecto é comum no livro, surgindo e norteando toda sua teologia e processos cúlticos.

Outro aspecto fundamental é aquele apresentado em Levítico 13:15-17. O texto aborda orientações acerca da lepra, o que, embora não seja elemento possuidor de caráter soteriológico, mas sim sanitário, é desenvolvido a partir de um princípio e procedimento análogo. A pessoa que continha a doença era declarada imunda perante a sociedade, e, quando ela estava aparentemente curada, o sacerdote teria que "declarar" a pessoa, antes leprosa, limpa. Sem a declaração sacerdotal de que tal sujeito estava purificado, ele nunca seria reintegrado ou reconsiderado como uma pessoa saudável; tudo dependia, portanto, da declaração sacerdotal.

Além do aspecto já mencionado, o livro de Levítico carrega outros elementos essenciais para a compreensão soteriológica. Os textos de Levítico 16:21-22 e Levítico 23:26-32, por exemplo, apresentam a finalidade última do santuário terrestre. Nestes capítulos há uma descrição do yôm kîpûr (dia da expiação), dia em que os pecados do povo eram impostos sobre a vida do bode para Azazel e carregados para o deserto, onde o animal morreria junto com os pecados. Em contrapartida, o bode para $Y H W H$ era morto, como sacrifício pelos pecados, possibilitando e executando tal purificação (NICHOL, 2011).

Mediante tal prática, todo o processo de salvação é representado, mesmo que em formato embrionário. Elementos como substituição, juízo, mediação e purificação são trabalhados em paralelo, construindo, de forma eficaz, conceitos de restauração geral da humanidade.

Em suma, os capítulos 13, 16 e 17 de Levítico contêm as principais referências à salvação que são passíveis de localização no livro. Dentre estas, destaca-se a noção de que, em contexto cúltico/cerimonial, a mediação é apresentada como estritamente necessária, mediante a declara- 
ção de "justificação/pureza" do sacerdote. Além disso, o yôm kîpûr é posto como um tipo terreno da grande purificação escatológica, onde a situação de resolução seria finalmente alcançada. Sobretudo, o conceito primordial deste livro é a noção de que não há salvação sem derramamento de sangue, pois a vida apenas pode ser salva mediante entrega de vida.

\section{A Soteriologia em Números}

O livro de Números narra os preparativos dos israelitas para a retomada de sua jornada inicial, conquistando a terra de Canaã, prometida por YHWH. Murmúrios, reclamações e rebeliões ocorrem, frequentemente, na narração do livro. Ao tratar essas ocorrências com sinceridade, YHWH se mostra como alguém que julga, embora também perdoe e encontre uma forma de continuar a ter Israel como povo.

Assim como ocorre nos demais livros da Torá, diversas propostas divergentes são feitas a fim de determinar uma estrutura para o livro de Números. Dentre essas, nota-se aquela proposta por Pfeiffer (1981) em seu comentário, onde é defendida a existência de três seções no texto, compostas por diversas subseções: Israel no deserto (1:1-21:35), intriga estrangeira contra Israel (22:2-25:18) e preparativos para a entrada na terra (26:1-36:13).

House (2005), por sua vez, partindo de sua ênfase que evidencia o agir de YHWH no livro, defende uma composição de cinco partes, divididas em: $1^{\text {a }}$ Seção $(1: 1-10: 11) ; 2^{\text {a }}$ Seção (10:1— 12:16); 3a Seção (13:1-20:13); 4a Seção (20:14-22:1) e, finalmente, 5a Seção (22:2-36:13). Tendo em vista o objetivo do presente artigo, a proposta de Pfeiffer (1981) será levada em consideração, conforme exposto na tabela 6, abaixo.

Tabela 6 - Divisão do Livro

\begin{tabular}{|l|l|}
\hline Seção & Exposição Temática \\
\hline Nm 1:1 $-21: 35$ & Israel no Deserto. \\
\hline Nm 22:2 - 25:18 & Intriga estrangeira contra Israel. \\
\hline Nm 26:1 - 36:13 & Preparativos para a entrada na terra. \\
\hline
\end{tabular}

Fonte: Adaptado de Pfeiffer (1981).

Seguindo procedimento comum aos livros anteriores, a fim de alcançar o objetivo proposto, foi feita análise das ocorrências de termos pertencentes ao campo semântico da salvação no livro. As ocorrências podem ser sistematizadas, conforme tabela 7, abaixo:

Tabela ? - Ocorrências de termos

\begin{tabular}{|l|l|l|}
\hline Raiz & Significado & Passagem(ns] \\
\hline \multirow{2}{*}{ - nāsal } & $\begin{array}{l}\text { Retirar, extrair, ideia de resgate ou } \\
\text { libertação. }\end{array}$ & Nm 35:25 \\
\hline \multirow{2}{*}{ - gá'al } & $\begin{array}{l}\text { Ideia de resgatador, aquele que paga } \\
\text { o resgate. }\end{array}$ & $\begin{array}{l}\text { Nm 5:8; 35:12; 35:19; 35:21; 35:24; } \\
35: 25 ; 35: 27\end{array}$ \\
\hline
\end{tabular}

Fonte: Autor, 2020.

Analisando a única ocorrência da palavra נצל (nāsal) no livro, nota-se que o conceito sugerido em Números 35:25 registra uma ideia de resgate daquele que havia cometido, acidentalmente, um homicídio (BÍBLIA DE ESTUDO ANDREWS, 2015). Esse, embora fosse poupado da 
morte e ficasse livre dentro de uma cidade de refúgio, só estaria livre para voltar para casa quando o sumo sacerdote morresse (de forma natural). Tal sistema reconhecia a seriedade de tirar a vida humana, mesmo que por acidente, pois o assassino ainda assim seria imputado como assassino e estaria privado de viver em sociedade por um longo período.

Além disso, esse período de resgate ofertado ao assassino dava aos parentes da vítima tempo para se recuperar da ira e pensar melhor na situação, visto que eles não poderiam sequer aproximar-se da cidade de refúgio. Tais aspectos abordam, de forma intuitiva, os elementos básicos da soteriologia; a situação problemática e sua causa são evidenciadas (assassinato não intencional, necessidade de julgamento do assassino), além de apresentado um meio para resolução (retenção nas cidades de refúgio) e uma promessa de situação resolvida (liberação após morte do sumo sacerdote). Além de tais aspectos, essa lei destacava o papel do sumo sacerdote na condução da culpa do povo.

Dentre as ocorrências do termo gáal, o texto de Números 5:8 registra conceitos importantes. Este texto sugere que, quando uma pessoa cometia um pecado contra o próximo, o ato era considerado como um pecado contra $Y H W H$; em razão disso, essa ação exigia a oferta de sacrifício, bem como a eventual restituição à pessoa prejudicada.

As demais ocorrências do termo gáal (Nm 35: 12, 19, 21, 24, 25 e 27) surgem no contexto da atuação do vingador, cuja raiz evoca o sentido de resgatar algo mediante atuação de algum parente. $\mathrm{O}$ vingador seria responsável por vingar o assassinato de um parente, em caso de morte não acidental; atuaria, deste modo, como resgatador da honra ou do custo causado pela vida perdida.

O elemento soteriológico mais relevante do livro é visto na narrativa do capítulo 21, onde a história da serpente de bronze é descrita; mesmo que os termos em análise não surjam aqui. Em um contexto de uma crise resultante do pecado do povo (situação problemática e causa), todo aquele que fosse picado por uma das muitas serpentes que foram lançadas pela divindade no território israelita, deveria olhar para uma escultura de serpente erguida (meio de resolução), o que traria cura e salvação (situação de resolução).

Em todo caso, ao analisar o livro, observa-se que, muito embora Números não apresente de forma inovadora conceitos soteriológicos, ele aborda uma continuidade daqueles estabelecidos nos livros anteriores e já apresentados acima. De igual forma, o livro de Deuteronômio reafirma tais aspectos sem ampliá-los consideravelmente, conforme pode ser notado a seguir.

\section{A Soteriologia em Deuteronômio}

O livro de Deuteronômio é histórico, legislativo e exortativo, e exibe várias propostas estruturais distintas. Alguns autores, a exemplo de Nichol (2011), apresentam uma estrutura baseada nos discursos de Moisés dirigidos a Israel. Nesse sentido, é proposta uma divisão para o livro composta por seis partes, que se configura como: introdução (1:1-5), primeiro discurso (1:6 4:43); segundo discurso "revisão da lei" (4:44-26:19); terceiro discurso "bênçãos e maldições da aliança" (27:1-28:68); quarto discurso "confirmação da aliança" (29:1-30:20), e exposição das responsabilidades da liderança do povo $(31: 1-34: 12)^{4}$.

Thompson (1982), por sua vez, embora também estruture o livro de Deuteronômio a partir dos discursos de Moisés, sugere que o livro foi composto a partir de três discursos e não quatro,

4 No comentário de seções da Bíblia de Estudos Almeida (2013) há uma proposta similar à apresentada por Nichol (2011). 
conforme os demais autores. Ainda assim, considerando a melhor fundamentação da estrutura proposta por Nichol (2011), seu modelo será aqui adotado, conforme exposto na tabela 8.

\section{Tabela 8 - Divisão do livro de Deuteronômio}

\begin{tabular}{|l|l|}
\hline Seção & Tema \\
\hline Dt 1:1-5 & Título e introdução \\
\hline Dt 1:6-4:43 & Primeiro discurso: Moisés anuncia a sua saída \\
\hline Dt 4:44-26:19 & Segundo discurso: revisão da lei \\
\hline Dt 27:1 - 28:68 & Terceiro discurso: bênçãos e maldições \\
\hline Dt 29:1- 30:20 & Quarto discurso: aliança em Moabe \\
\hline Dt 31:1-34:12 & As responsabilidades da Liderança \\
\hline
\end{tabular}

Fonte: Adaptado de Nichol (2011).

Assim como nos livros anteriores, para realizar uma análise da soteriologia em Deuteronômio, uma busca pelos termos que evocam a ideia de resgate, libertação e salvação foi feita no texto. A tabela abaixo mostra as ocorrências encontradas. ${ }^{5}$

\section{Tabela 9 - Ocorrências no contexto soteriológico}

\begin{tabular}{|c|c|c|}
\hline Raiz & Significado & Ocorrências \\
\hline נצל - nāsal & $\begin{array}{l}\text { Retirar, extrair, ideia de resgate ou liberta- } \\
\text { ção. }\end{array}$ & Dt 23:15; 23:16; 25:11; 32:39 \\
\hline - גáa & $\begin{array}{l}\text { Ideia de resgatador, aquele que paga o res- } \\
\text { gate. }\end{array}$ & Dt 19:6; 19:12 \\
\hline מלט - mālat & Libertação, com ênfase em dar segurança. & Dt 32:15 \\
\hline
\end{tabular}

Fonte: elaborado pelo autor, 2020.

Tendo em mente que as raízes hebraicas que imprimem a ideia de resgate, libertação e salvação não possuem extenso valor soteriológico no livro - sendo empregadas em outros contextos -, a ocorrência que melhor evoca a ideia de salvação aparece de forma mais explícita em Deuteronômio 32:1, na última seção do livro. Neste verso, a expressão "rocha da minha salvação" é introduzida. Segundo Nichol (2011), a palavra "rocha" surge cerca de 30 vezes no Antigo Testamento como um título atribuído ao messias, o que sugere a possibilidade de que Moisés, ao escrever, tivesse em mente o messias vindouro como seu Salvador.

Um segundo aspecto que contribui para a percepção do conceito no livro surge, também, no capítulo 32, onde é encontrado o cântico de Moisés. House (2005) argumenta que este cântico oferece, em forma de poesia, uma summa teológica, mostrando o resultado de se quebrar ou manter a aliança: os fiéis recebem as bênçãos e os rebeldes as maldições. Desse modo, "o sofrimento é entendido como uma realidade provocada por culpa própria [...] [já que,] na literatura sapiencial, o justo é recompensado e o ímpio é castigado" (WARDISON; TEIXEIRA, 2011, p. 29). A ideia presente neste cântico - assim como no livro como um todo -, portanto, é que seguir a lei ou os

\footnotetext{
5 Nos textos em que a raiz hebraica גאל (gal) aparece, o sentido é o de "vingador de sangue" (conforme já analisado anteriormente). Já nos textos em que aparece a raiz hebraica גצל (nāsal), o termo não é apresentado com peso soteriologico.
} 
requisitos da aliança traria uma salvação continua de $Y H W H$ destinada ao povo, enquanto os que quebrassem os termos da aliança perderiam a salvação.

Portanto, em Deuteronômio, a soteriologia está expressa de forma mais clara no cântico de Moisés; não apenas no uso da expressão "rocha da minha salvação", mas, também, mediante a descrição das bênçãos e maldições. Como Von Rad (1966) afirma, o cântico de Moisés é um dos eventos bíblicos que mais suscitam a imagem de um Deus que salva, contribuindo, portanto, para a compreensão deste conceito.

\section{Síntese Soteriológica na Torá}

Ao concluir a análise do tema, é possível propor em síntese que os quatro pilares que compõem o pensamento soteriológico (Situação Problemática, Causa do Problema, Meio de Resolução e Situação de Resolução), são apresentados e desenvolvidos em meio aos livros estudados, de forma completa ou não (com maior ênfase nos três primeiros, sendo Números e Deuteronômio reafirmações das ideias expostas de antemão, com explanações aplicadas), conforme sintetizado na tabela abaixo.

Tabela 10 - Síntese de ocorrências dos quatro pilares do pensamento soteriológico

\begin{tabular}{|c|c|c|c|c|c|}
\hline Pilares & Gênesis & Êxodo & Levítico & Números & Deuteronômio \\
\hline $\begin{array}{l}\text { Situação Proble- } \\
\text { mática }\end{array}$ & $\begin{array}{l}\text { o rebelar-se contra } \\
Y H W H[\mathrm{Gn} 3]\end{array}$ & $\begin{array}{l}\text { Cativeiro Egípcio } \\
\text { [ÊE 2:23-25] }\end{array}$ & $\begin{array}{l}\text { O pecado do } \\
\text { povo/mundo } \\
\text { [“implícito"] }\end{array}$ & $\begin{array}{l}\text { crise - serpentes } \\
{[\mathrm{Nm} 21]}\end{array}$ & $\begin{array}{l}\text { Perversão moral } \\
\text { do povo }\end{array}$ \\
\hline Causa do Problema & $\begin{array}{l}\text { necessidade da } \\
\text { salvação cosmo- } \\
\text { lógica/individual } \\
\text { [Gn 3:15] }\end{array}$ & ----- & $\begin{array}{l}\text { A queda do } \\
\text { homem/O Pecado } \\
\text { [“implícito"] }\end{array}$ & $\begin{array}{l}\text { Pecado do povo } \\
{[\mathrm{Nm} 21: 5]}\end{array}$ & $\begin{array}{l}\text { "união" com ou- } \\
\text { tros povos }\end{array}$ \\
\hline Meio de Resolução & $\begin{array}{l}\text { Sacrifício [Gn } \\
4: 3-5]\end{array}$ & Moisés [Êx 3] & $\begin{array}{l}\text { Santuário/Sacrifí- } \\
\text { cio [Lv 16:21-22/ } \\
\text { Lv 23:26-32] }\end{array}$ & $\begin{array}{l}\text { Serpente de Bron- } \\
\text { ze [Nm 21:8] }\end{array}$ & $\begin{array}{l}\text { Obediência aos } \\
\text { termos da Aliança } \\
\text { [Dt 32] }\end{array}$ \\
\hline $\begin{array}{l}\text { Situação de Reso- } \\
\text { lução }\end{array}$ & $\begin{array}{l}\text { Situação implícita } \\
\text { - Novo Éden [Gn } \\
\text { 3:15, ver Ap 21-22]. }\end{array}$ & $\begin{array}{l}\text { Povo Eleito/ } \\
\text { Liberto - Canaã [ } \\
\text { Exx } 2: 24 ; 12]\end{array}$ & $\begin{array}{l}\text { Restauração/ } \\
\text { Expiação terrena } \\
\text { e escatológica } \\
\text { [Lv 16:21-22/Lv } \\
23: 26-32 \text { ] }\end{array}$ & $\begin{array}{l}\text { Todo que a olhar, } \\
\text { viverá [Nm } \\
21: 8,9]\end{array}$ & $\begin{array}{l}\text { Aliança mantida } \\
\text { [Dt 32] }\end{array}$ \\
\hline
\end{tabular}

Fonte: elaborado pelo autor, 2020.

Dessa forma, o desenvolvimento soteriológico da Torá pode ser sintetizado e organizado, a partir do estudo de cada livro, da seguinte forma:

\section{Tabela 11 - Síntese do desenvolvimento soteriológico da Torá}

\begin{tabular}{|l|l|l|}
\hline \multicolumn{1}{|c|}{ Livro } & \multicolumn{1}{|c|}{ Conceitos Gerais } & \multicolumn{1}{|c|}{ Conceitos Específicos } \\
\hline \multirow{3}{*}{ Gênesis } & $\begin{array}{l}\text { Apresentação da problemática e proposta de resolução; } \\
\text { Introdução de Conceitos; } \\
\text { Desenvolvimento do papel do mediador (Indivíduo, } \\
\text { Patriarca, Povo). }\end{array}$ & $\begin{array}{l}\text { YHWH é libertador/resgatador } \\
\text { Caráter terreno e cosmológico da salvação } \\
\text { Graça. }\end{array}$ \\
\hline Êxodo & $\begin{array}{l}\text { Eleição } \\
\text { Libertação }\end{array}$ & $\begin{array}{l}\text { Eleição de Israel } \\
\text { Libertação Jurídica }\end{array}$ \\
\hline
\end{tabular}




\begin{tabular}{|l|l|l|}
\hline Levítico & $\begin{array}{l}\text { Purificação/Expiação } \\
\text { Santuário } \\
\text { Resgatador }\end{array}$ & $\begin{array}{l}\text { Mediação necessária } \\
\text { Salvação por substituição }\end{array}$ \\
\hline Números & ----- & $\begin{array}{l}\text { Serpente de Bronze - Fé e se voltar a } \\
\text { YHWH }\end{array}$ \\
\hline Deuteronômio & O YHWH que livra na Aliança & $\begin{array}{l}\text { YHWH cuida de seu povo quanto este é fiel } \\
\text { YHWH como rocha da salvação }\end{array}$ \\
\hline
\end{tabular}

Fonte: elaborado pelo autor, 2020.

\section{Considerações finais}

Após análise deste material, conforme apresentado ao longo da pesquisa, nota-se que os livros que compõem a Torá apresentam um desenvolvimento teológico linear e progressivo, no que se refere à temática soteriológica. O livro de Gênesis atua como recurso introdutório e alusivo de todos os demais livros, estabelecendo os princípios fundamentais que são melhor trabalhados/ desenvolvidos posteriormente.

Nesse sentido, o livro de Gênesis apresenta uma exposição da problemática soteriológica e sua resolução, mesmo que de forma embrionária. Além disso, desenvolve o aspecto da "execução" da salvação (mediação) de um ponto mais individual, passando por um aspecto familiar e culminando na eleição de um povo. O livro de Êxodo trabalha de forma mais detalhada os conceitos de libertação e eleição, enquanto o aspecto de mediação sacerdotal/cúltica é mais bem desenvolvido no livro de Levítico. Os livros de Números e Deuteronômio, embora não desenvolvam de forma tão distintiva novos elementos, aprofundam os conceitos estabelecidos nos livros anteriores, acrescendo em seu desenvolvimento teológico aspectos relevantes para sua compreensão total.

Findando tal análise, portanto, fica evidenciada a relevância da pesquisa dos elementos presentes na Torá para compreensão geral da temática, especialmente considerando sua função introdutória e basilar dos elementos que compõem esse campo de estudos.

\section{Referências}

BARTON, J.; MUDDIMAN, J. The Oxford Bible Commentary, New York: Oxford University Press, 2007.

BÍBLIA DE ESTUDO ANDREWS. Tradução de Cecília Eller Nascimento. Tatuí: Casa Publicadora Brasileira, 2015.

BÍBLIA DE ESTUDO ALMEIDA. São Paulo: Sociedade Bíblica do Brasil, 2013.

BLAZEN, I. T. Salvação. In: Tratado de teologia Adventista do Sétimo Dia. Tatuí: Casa Publicadora Brasileira, 2011.

BROWN, R. E.; FITZMYER, J.; E. MURPHY, R. Novo Comentário Bíblico São Jerônimo: Antigo Testamento. São Paulo: Academia Cristã; Paulus, 2007.

ERICKSON, M. J. Teologia Sistemática. São Paulo: Vida Nova, 2015. 
FERREIRA, J. S. Cristo nossa salvação: o que feito por nós e o que está disposto a fazer em nós. Niterói: Ados, 2006.

FINGUERMAN, A. A eleição de Israel: A polêmica entre judeus e cristãos sobre a doutrina do "povo eleito". São Paulo: Associação Editorial Humanitas, 2005.

GRONINGEN, G. V A Família da Aliança. São Paulo: Cultura Cristã, 1997.

HOUSE, P. R. Teologia do Antigo Testamento. São Paulo: Academia Cristã; Paulus, 2005.

MACARTHUR, J. The MacArthur Bible Commentary. Tennessee: Thomas Nelson, 2005.

MCGRATH, A. E. Teologia Sistemática, Histórica e Filosófica: uma introdução à teologia cristã. São Paulo: Shedd, 2005.

MODES, J. V. A Salvação no Antigo Testamento: fé, e nada além dela, é que torna a mesma uma realidade! Revista Batista Pioneira, Belo Horizonte, v. 3, n. 1, p. 35-50, jun. 2014.

NICHOL, F. D. (org.). Comentário bíblico adventista do sétimo dia. Vol. 1. Tatuí: Casa Publicadora Brasileira, 2011.

PFEIFFER, C. F. Números. In.: Comentário Bíblico Moody Antigo Testamento. Grand Rapids: Editora Portavoz, 1981.

THOMAS, M. A. These are the Generations: Identity, Covenant, and the 'toledot' Formula. Reino Unido: T\&T Clark. 2011.

THOMPSON. J.A. Deuteronômio: Introdução e comentário. São Paulo: Vida Nova, 1982.

VAZ, A. S. O vocabulário bíblico da redenção. Didaskalia, Lisboa, v. 14, n. 1, p. 55-76, 1984.

VON RAD, G. Teologia do Antigo Testamento. Vol. 1. São Paulo: Aste, 1973.

VON RAD, G. Deuteronomy: A Commentary. Vol. 5. Philadelphia: Westminster Press, 1966.

WARDISON, A.; TEIXEIRA, C. O desejo de Deus pelo homem: perspectivas histórico-teológicas no antigo testamento. Revista Eletrônica Espaço Teológico: Reveleto, São Paulo, v. 5, n. 8, p. 26-40, jul. 2011. 